\title{
Validation of the Negative Acts Questionnaire (NAQ) in a Sample of Greek Teachers
}

\author{
Kakoulakis Charilaos ${ }^{1}$, Galanakis Michael'2, Bakoula-Tzoumaka Chryssa ${ }^{3}$, \\ Darvyri Panagiota ${ }^{1}$, Chrousos P. George ${ }^{1,4^{*}}$, Darviri Christina ${ }^{1^{*} \#}$ \\ ${ }^{1}$ Postgraduate Course Science of Stress and Health Promotion, School of Medicine, University of Athens, \\ Athens, Greece \\ ${ }^{2}$ Panteion University of Social and Political Sciences, Athens, Greece \\ ${ }^{3}$ First Department of Pediatrics, Children's Hospital Aglaia Kyriakou, School of Medicine, University of Athens, \\ Athens, Greece \\ ${ }^{4}$ First Department of Pediatrics, Children's Hospital Aghia Sofia, School of Medicine, University of Athens, \\ Athens, Greece \\ Email: "cdarviri@yahoo.com
}

Received 30 December 2014; accepted 18 January 2015; published 23 January 2015

Copyright (C) 2015 by authors and Scientific Research Publishing Inc.

This work is licensed under the Creative Commons Attribution International License (CC BY).

http://creativecommons.org/licenses/by/4.0/

(c) (i) Open Access

\section{Abstract}

Workplace bullying/mobbing is a globally recognized problem. In numerous studies executed in Europe and North America, workplace bulling/mobbing is associated with psychological, psychosomatic, and behavioral effects on the individual, while it causes severe side-effects on the professional environment. Negative Acts Questionnaire-Revised (NAQ-22) has been widely used by researchers to assess the phenomenon. The purpose of this study is to assess the psychometric properties of NAQ-22 in a sample of 265 primary and secondary school teachers. The teachers filled the NAQ-22, DASS-21, PSS, and Self-Esteem Questionnaires anonymously. Reliability and validity indexes of the tool were satisfactory (Cronbach's $\alpha=0.915$ ). Specifically, the study showed a negative correlation between mobbing and self-esteem $\left(r=-0.364^{* *}\right)$ and positive correlation between mobbing and stress $(r=0.406)$, anxiety and depression $(r=0.389)$.

\section{Keywords}

Workplace Bullying, Mobbing, Harassment, NAQ

\footnotetext{
${ }^{*}$ These authors contributed equally and shared last authorship.

${ }^{\#}$ Corresponding author.
}

How to cite this paper: Kakoulakis, C., Galanakis, M., Bakoula-Tzoumaka, C., Darvyri, P., Chroussos, G., \& Darvyri, C. (2015). Validation of the Negative Acts Questionnaire (NAQ) in a Sample of Greek Teachers. Psychology, 6, 63-74. 


\section{Introduction}

Workplace bullying is a globally recognized problem, and numerous relevant studies have been published during the past decade. World Health Organization classifies it as psychological violence and the European Agency for Safety and Health at Work acknowledges that there is considerable damage both for the employee's mental health and for the employer.

As far as the percentages of the phenomenon in the general population are concerned, it seems that there is no unanimity among studies and, in certain cases, findings show significant discrepancies, due to the use of different assessment tools as well as to cultural differences among individual countries (Hoel et al., 2001; Zapf, Escartin et al., 2011). In USA, approximately one out of ten employees experiences repeated abusive behavior every year and $30 \%$ to $40 \%$ will be bullied over the years of their professional life (Lutgen-Sandvik \& Tracy, 2011).

Bullying symptoms in individuals can be divided in the following categories: 1) Psychological effects (anxiety, panic attacks, depression, fear, suicidal ideation or suicide, low mental well-being, low self-esteem, humiliation, helplessness, high levels of burn-out etc.). 2) Psychosomatic effects (dizziness, abdominal pain, back pain, headache, insomnia, fatigue, perspiration, malaise, irritable bowel, high levels of blood pressure, sleeping disorders, lack of appetite, weight loss or gain. 3) Behavioral effects (irritability, alienation and lack of trust, aggressiveness, increased alcohol consumption and smoking, low problem-solving ability, social isolation, deterioration of personal relationships etc.). 4) Chronic disease (asthma, diabetes, rheumatoid arthritis, sciatica, as well as immune system disorders, such as cancer, cardiovascular disease and more) (Di Martino et al., 2003; Keashly \& Harvey, 2005; Kivimaki et al., 2003; Leymann, 1990; Matthiesen \& Einarsen, 2004; Moayed et al., 2006; Sharon \& O’Connell, 2007). 5) Increased sickness absenteeism which can lead to dismissal or resignation. (Hoel \& Cooper, 2000).

Workplace bullying in relation to stress can be perceived as a reaction to an occupational stressor and as a stressor itself as well (Hoel et al., 2002). Bullying appears to be associated with post-traumatic stress as well (Matthiesen et al., 2003).

Across researchers there is no unanimity about the definition of harassment/bullying at workplace. There is no universally recognized terminology either, and several terms are used to describe the same phenomenon (Ferrari, 2004; Matthiesen \& Einarsen, 2007).

The term "mobbing" was first used in the "60s by the Austrian ethologist Konrad Lorenz to describe the herds" aggressive behavior. In the 1970's, Swedish doctor Peter-Paul Heinemann and Dan Olweus established the term for bullying at school. Later, Heinz Leimann borrowed the term mobbing to describe harassing behaviors at workplace (Di Martino et al. 2003; Einarsen et al., 2011). The term bullying has been used by British, Irish, Australian and Northern European researchers, while their German colleagues have used the term mobbing to describe the same phenomenon (Einarsen et al., 1994; Einarsen \& Skogstad, 1996; Johnson, 2009; Salin, 2003).

Apart from the above, there are the following indicative terms, closely associated with mobbing/workplace bullying: harassment or work harassment, non-sexual harassment, psychological harassment, victimization, psychological terror, employee abuse, workplace aggression (Beswick et al., 2006; Johnson, 2009; Keashly, 2001; Vartia, 2001).

The operational definition of workplace bullying by Heinz Leymann is clearly influenced by the conceptual definition by Dan Olweus described above. Heinz Leymann defines moral harassment in occupational life as a systematic hostile and immoral act by one or more individuals against usually one person, who is helpless and unable to defend him/herself, as a result of the bullying acts. According to the Leymann criterion, these bullying acts take place on a regular basis (at least once a week) and over a long period of time (at least six months) (Di Martino et al. 2003; Leymann, 1990). Victims are differentiated from non-victims, if they declare to have been exposed to at least one negative act in a week for a period of six months according to Leymann, or to two negative acts according to Mikkelsen and Einarsen, or to three or more negative acts according to Agervold (Nielsen et al., 2011).

Einarsen et al. (2001) proposed a definition which is widely used nowadays, as one of the most highly accepted definitions of the phenomenon: "Bullying at work means harassing, offending, socially excluding someone or negatively affecting someone's work tasks. In order for the label bullying (or mobbing) to be applied to a particular activity, interaction or process, the bullying behavior has to occur repeatedly and regularly (e.g., 
weekly) and over a period of time (e.g. about six months). Bullying is an escalating process in the course of which the person confronted ends up in an inferior position and becomes the target of systematic negative social acts. A conflict cannot be called bullying, if the incident is an isolated event or if two parties of approximately equal "strength" are in conflict." (Einarsen et al., 2011).

Public sector employees seem to be more at risk than their colleagues in the private sector (Zapf et al., 2011). Employees at three areas are at greater risk: penitentiary services, post/telecommunications and education (Hoel \& Cooper, 2000). In Great Britain, the Association of Teachers and Lecturers reported that $76 \%$ of the respondents mentioned that they have been recipients of this type of behavior by their superiors, and $22 \%$ by their colleagues. $25 \%$ mentioned that they have been bullied by a student and $23 \%$ by a parent or guardian (ATL Annual Conference, April 2011). Similar findings have been published in 2003 by ATL in Great Britain.

In Education colleagues and headmasters are considered to be perpetrators (Blasé \& Blasé, 2006; Čech, 2010; Djurkovic, 2004). Parents also emerge as perpetrators of inappropriate behavior against teachers. According to previous studies, workplace bullying is positively correlated with stress and depression and negatively correlated to self-esteem (Blasé \& Blasé, 2006; Čech, 2010; Djurkovic, 2004). Moreover in some studies workplace bullying is also associated with body characteristics (height and weight) while in others such a relationship is not reported.

There are three main methods for the quantitative measurement of workplace bullying. The first one is the subjective method of asking participants whether they perceive themselves as victims of workplace bullying, based on a given definition of bullying. The second one is the operational method or criterion-based method where various questionnaires are used. The participants are given a list of negative acts at workplace and they are prompted to tick the ones they have been subjected to. The third one is a combination of the two aforementioned methods and is considered to be the best approach to workplace bullying measurement (Lutgen-Sandvik et al., 2007; Mikkelsen \& Einarsen, 2001; Nielsen et al., 2011).

The most popular tools for the measurement of workplace bullying are Leymann Inventory of Psychological Terror-LIPT, and Negative Acts Questionnaire-NAQ, as well as NAQ-R (Einarsen \& Hoel, 2001; Einarsen, Hoel \& Notelaers, 2009; Nolfe et al., 2012). The NAQ scale has been widely used in studies in Northern European countries, USA and Canada, from 1990 to 2009 (Nielsen et al., 2011). Two studies on workplace bullying have been conducted in Greece. In both cases NAQ-32 questionnaire was used instead of NAQ-22 Revised. (Apospori \& Papalexandris, 2008; Galanaki \& Papalexandris, 2011).

The purpose of this study was to assess the validity and reliability (psychometric properties) of the Greek version of Negative Acts Questionnaire-Revised (NAQ-22) in a sample of Greek teachers. We used NAQ-R in combination with PSS-because, according to existing bibliography, it is associated with workplace bullying/mobbing-(criterion validity). For the same reason we used the self-esteem and depression tests (DASS 21). We expect that mobbing victims will score high in stress and depression levels and low in self-esteem. At the same time we measured the participants' height and weight, due to the hypothesis that body type may affect mobbing victimization.

\section{Method}

\subsection{Sample}

The tests were administered to a sample of 265 school teachers from Athens (83.10\%) and from regional areas of Greece (16.90\%). $40 \%$ of the participants were male and $60 \%$ female. The sample's average age was 44.58 years old and standard deviation was 8.85 . As far as marital status is concerned, $27 \%$ declared single, $68 \%$ married, $1.2 \%$ widow/er and 3.9\% divorced. Regarding their education level, $1.2 \%$ were Technical Vocational School graduates, $75.3 \%$ University graduates, $19.3 \%$ were post-graduate degree holders, and $4.2 \%$ were Doctorate Diploma holders. The majority of the sample's individuals, $86.90 \%$, were secondary school teachers, while $12.7 \%$ were primary school teachers, and $0.4 \%$ were lecturers. $92.5 \%$ of the sample worked at public schools, $2.00 \%$ at private schools, $1.5 \%$ at Vocational Training Institutes, and $4.00 \%$ at private crammer schools. $33.10 \%$ were technology teachers, $22.6 \%$ literature, grammar and history teachers, $13.70 \%$ science and mathematics teachers, $9.3 \%$ foreign languages teachers and $17.30 \%$ were teachers of other subjects (geography, law etc.). Finally, the participants were asked to indicate whether they were optimistic personalities $(80.80 \%)$ or pessimistic $(13.20 \%)$, their height $($ mean value $=170 \mathrm{~cm}$, S.D. $=8.21 \mathrm{~cm})$ and weight $($ mean value $=73.09 / \mathrm{S} . \mathrm{D} .=$ 15.32). 


\subsection{Demographic Data Scale}

In order to complete this study, we created a demographic data scale based on the variables which affect the phenomenon, according to existing bibliography. More specifically, the participants were asked to state their gender, age, marital status (single, married, widow/er, divorced), place of residence, (Attica/regional areas), educational level, years of professional experience, the level of the school they work at, (primary, secondary, post-secondary), type of school (public, private), the subjects they teach (technology, literature, writing, and history, science and mathematics, foreign languages etc.), whether they perceive themselves as optimistic or pessimistic personalities, and finally their height and weight.

\subsection{Procedure-Translation and License of NAQ-22}

On the 18th of November 2012, we received permission from Professor Ståle Einarsen to use the Revised NAQ-22, as well as the 23-item questionnaire. The permission was granted on the condition that the questionnaire would be used exclusively for research purposes. The Revised NAQ-22 was standardized after the Greek version was drafted, following the procedure of Back Translation by specialized psychologists, experts in Greek and English language.

We administered the questionnaires between January 2013 and May 2013. The participants were chosen randomly, according to their availability and their willingness to participate in the research, in order to avoid affecting the results by unwilling participation. We informed the participants of the purpose of the research. Data was collected in an anonymous and confidential manner. During the questionnaires' completion, no questions arose due to lack of clarity. After completion, the participants placed the questionnaire in an envelope. The average completion time was 20 minutes. The return rate of the distributed questionnaires was $90 \%$. Five questionnaires were omitted due to incomplete items.

\section{Instruments}

\subsection{The Negative Acts Questionnaire-Revised (NAQ-R)}

NAQ-R is the revised version of NAQ-32. NAQ-R has been standardized in several countries, such as Japan, United Kingdom and the USA. Studies in Norway revealed internal consistency ranging from Cronbach's alpha 0.88 to 0.90 . In the United Kingdom, it was used on a heterogeneous sample of 5288 employees and revealed high internal consistency (Cronbach's alpha 0.90). It also portrays excellent criterion validity and construct validity. In combination with Latent Class Cluster (LCC), the tool proved appropriate to divide employees into different levels (groups) of exposure to bullying (Einarsen et al., 2009; Nielsen et al., 2011).

In NAQ-R, there are no references to the term bullying, only harassing behaviors are listed. It includes 22 different types of undesirable and negative behaviors that range from indirect and subtle acts—-such as gossipto direct negative acts—-such as threats or physical abuse.

NAQ-R's bullying behaviors cover two categories of harassing acts: hostile acts against the person/personality of the target (e.g., spreading gossip and rumors) and hostile behaviors against the working output of the target (e.g., withholding information). The 22nd negative act refers directly to physical abuse.

In order to determine the frequency of the exposure to bullying behaviors, a 5-point Likert scale is used (1 Never; 2 Now and then; 3 Monthly; 4 Weekly; 5 Daily). The respondents are prompted to state how often they have been subjected to the 22 negative acts of the questionnaire, based on their experience in their workplace, over the last six months (Einarsen et al., 2009).

Scores range from 23 to 115 points. It also includes a 23rd general question where an accurate definition of bullying is provided and the participants are asked to state the degree to which they feel they have been subjected to this kind of behavior according to the self-labelling method. This question can serve as a general mobbing/workplace bullying indicator as well as a criterion validity indicator in association with the other questions of the test.

\subsection{Perceived Stress Scale}

Stress was measured on the basis of the 14-item Perceived Stress Scale (PSS) by CohenS. (Cohen, Kamarck, \& Mermelstein, 1983). The individual is invited to answer 7 positively stated and 7 negatively stated questions 
concerning his/her emotions and thoughts over the last month on a Likert-type scale $(1=$ Never to 5 = Very often). Overall score is obtained by summing all the answers' scores, having previously reversed the responses of positive questions. High scores indicate higher level of perceived stress. The questionnaire has been standardized in Greek with adequate internal consistency (Cronbach’s alpha = 0.79) (Andreou et al., 2011).

\subsection{Self-Esteem Test (GalaSelfEsteem Test)}

The GalaSelfEsteem Test was created by A. Stalikas and M. Galanakis (2012) and has been standardized in Greece. The scale consists of 50 items measuring adults' self-esteem as one factor. Participants answer questions regarding their self-esteem using a 5 point likert scale. Total scores are estimated by adding the answers and range between 50 (extremely low self-esteem) to 250 points (extremely high self-esteem. The test's reliability was Cronbach's alpha $=0.79$.

\subsection{DASS 21}

DASS was designed to measure negative emotional states of depression, anxiety and stress. Apart from the basic version including 42 self-report points, there is the concise version, DASS 21 . The concise version DASS 21 is divided into subscales: depression, anxiety and stress. The respondents are requested to self-report on a Likert scale (0 did not apply to me at all to 3 applied to me very much or most of the time) (Lyrakos et al., 2011). We used the Greek standardized version of DASS 21. The test's reliability was Cronbach alpha $=0.83$.

\section{Results}

We used the statistical software package SPSS Vol.20 to perform the analyses. Initially we calculated mean values and standard deviations for the basic questionnaires of the study, as well as the questionnaire to be standardized. The mean value for bullying behavior (NAQ) was $\mathrm{M}=34.80$ and standard deviation $\mathrm{SD}=10.51$.

We proceeded with analysis in order to check for invalid questions and polarity issues. We examined the degree of systematic selection of all possible answers/ratings, as well as distribution per question. As shown in Table 1, the results revealed that variance per question was low and that the participants systematically indicated that there was none or minimum frequency of bullying incidents at their workplace.

The results indicate that either bullying behaviors are scarce or that there is a tendency to provide a socially acceptable answer and to withhold relative information. In question 22 all participants stated almost zero frequency. This question refers to physical abuse or threats of violence. Results for question 22 are presented in Table 2.

Even though variance and frequencies of this question show potential polarity in terms of socially acceptable statements, we did not mark it as invalid, because the behavior described might be scarce at workplace and the answers may refer to extreme forms of bullying. As for the remaining questions, variance ranged between 0.259 1.272. Mean value per question ranged from 1.18 to 1.80 , and standard deviation from 0.479 to 1.128 .

Subsequently, we carried out inter-correlation analysis of the questions. According to the methodological rule, correlations among questions should be positive, of low to medium level, indicating the measurement of a common notion/variable.

According to the results of the correlational analysis, there is a positive statistically significant correlation of medium level among most of the questions, with values ranging between $r=0.3-0.5$. The questions seem to measure the sides of the same variable with the same direction.

We performed Cronbach's internal consistency criterion analysis in order to examine the test's reliability. According to the results, the scale proved to be reliable. Specifically, Cronbach alpha was 0.915 . Further item analysis showed that the withdrawal of no item could increase the upper reported reliability. Results of the analysis are presented in Table 3.

Finally, as far as psychometric qualities are concerned, we performed a series of validity tests. We initially performed a criterion validity test, with the criteria of stress, anxiety, depression and self-esteem levels. We hypothesized that the individuals experiencing greater level of bullying at workplace would be experiencing more stress, anxiety, depression and lower self-esteem. Results of the analysis are presented in Table 4.

According to the results, the scale shows adequate criterion validity. Specifically, there is negative correlation 
Table 1. Item Analysis of NAQ.

\begin{tabular}{lccccc}
\hline & & Frequency & Percent & Valid Percent & Cumulative Percent \\
\hline \multirow{3}{*}{ Valid } & 1.00 & 196 & 74.0 & 85.6 & 85.6 \\
& 2.00 & 28 & 10.6 & 12.2 & 97.8 \\
& 3.00 & 5 & 1.9 & 2.2 & 100.0 \\
Missing & Total & 229 & 86.4 & 100.0 & \\
Total & System & 36 & 13.6 & & \\
\hline
\end{tabular}

Table 2. Analysis of NAQ-22's question 22.

\begin{tabular}{cccccc}
\hline & & Frequency & Percent & Valid Percent & Cumulative Percent \\
\hline \multirow{3}{*}{ Valid } & Never & 243 & 91.7 & 93.5 & 93.5 \\
& Now and Then & 17 & 6.4 & 6.5 & 100.0 \\
Missing & Total & 260 & 98.1 & 100.0 & \\
Total & System & 5 & 1.9 & & \\
\hline
\end{tabular}

Table 3. Reliability analysis of NAQ-22 and the questions' contribution to reliability level.

\begin{tabular}{|c|c|c|c|c|c|}
\hline & $\begin{array}{l}\text { Scale Mean If Item } \\
\text { Deleted }\end{array}$ & $\begin{array}{c}\text { Scale Variance If Item } \\
\text { Deleted }\end{array}$ & $\begin{array}{l}\text { Corrected Item-Total } \\
\text { Correlation }\end{array}$ & $\begin{array}{l}\text { Squared Multiple } \\
\text { Correlation }\end{array}$ & $\begin{array}{l}\text { Cronbach's Alpha If } \\
\text { Item Deleted }\end{array}$ \\
\hline NA1 & 31.71 & 95.964 & 0.433 & 0.304 & 0.914 \\
\hline NA2 & 32.17 & 97.214 & 0.467 & 0.426 & 0.913 \\
\hline NA3 & 31.47 & 90.345 & 0.540 & 0.493 & 0.913 \\
\hline NA4 & 31.60 & 89.799 & 0.638 & 0.580 & 0.909 \\
\hline NA5 & 31.73 & 93.134 & 0.551 & 0.527 & 0.911 \\
\hline NA6 & 31.99 & 95.134 & 0.561 & 0.435 & 0.911 \\
\hline NA7 & 32.10 & 94.907 & 0.613 & 0.622 & 0.910 \\
\hline NA8 & 31.98 & 93.476 & 0.666 & 0.560 & 0.909 \\
\hline NA9 & 32.32 & 99.120 & 0.442 & 0.463 & 0.913 \\
\hline NA10 & 32.30 & 97.095 & 0.543 & 0.428 & 0.911 \\
\hline NA11 & 31.91 & 95.438 & 0.607 & 0.523 & 0.910 \\
\hline NA12 & 32.06 & 94.476 & 0.654 & 0.527 & 0.909 \\
\hline NA13 & 31.91 & 93.534 & 0.628 & 0.574 & 0.909 \\
\hline NA14 & 31.66 & 92.364 & 0.623 & 0.541 & 0.909 \\
\hline NA15 & 32.28 & 98.720 & 0.481 & 0.443 & 0.913 \\
\hline NA16 & 31.97 & 93.947 & 0.626 & 0.601 & 0.909 \\
\hline NA17 & 32.07 & 96.368 & 0.543 & 0.422 & 0.911 \\
\hline NA18 & 31.79 & 89.717 & 0.661 & 0.613 & 0.909 \\
\hline NA19 & 31.97 & 93.198 & 0.597 & 0.485 & 0.910 \\
\hline NA20 & 32.24 & 97.154 & 0.511 & 0.473 & 0.912 \\
\hline NA21 & 31.81 & 94.388 & 0.485 & 0.410 & 0.913 \\
\hline NA22 & 32.44 & 101.425 & 0.459 & 0.383 & 0.914 \\
\hline
\end{tabular}


Table 4. Criterion validity analysis of NAQ-22 with the criteria of stress, anxiety, depression and self-esteem levels.

\begin{tabular}{|c|c|c|c|c|c|}
\hline & & NAQ & PSS & SelfEsteem & DASS \\
\hline \multirow{3}{*}{ NAQ } & Pearson Correlation & 1 & $0.406^{* *}$ & $-0.364^{* *}$ & $0.389^{* *}$ \\
\hline & Sig. (2-Tailed) & & 0.000 & 0.000 & 0.000 \\
\hline & $\mathrm{N}$ & 229 & 210 & 221 & 203 \\
\hline \multirow{3}{*}{ PSS } & Pearson Correlation & $0.406^{* *}$ & 1 & $-0.564^{* *}$ & $0.676^{* *}$ \\
\hline & Sig. (2-Tailed) & 0.000 & & 0.000 & 0.000 \\
\hline & $\mathrm{N}$ & 210 & 241 & 232 & 213 \\
\hline \multirow{3}{*}{ SelfEsteem } & Pearson Correlation & $-0.364^{* *}$ & $-0.564^{* *}$ & 1 & $-0.549^{* *}$ \\
\hline & Sig. (2-Tailed) & 0.000 & 0.000 & & 0.000 \\
\hline & $\mathrm{N}$ & 221 & 232 & 252 & 223 \\
\hline \multirow{3}{*}{ DASS } & Pearson Correlation & $0.389^{* *}$ & $0.676^{* *}$ & $-0.549^{* *}$ & 1 \\
\hline & Sig. (2-Tailed) & 0.000 & 0.000 & 0.000 & \\
\hline & $\mathrm{N}$ & 203 & 213 & 223 & 232 \\
\hline
\end{tabular}

${ }^{* *}$ Correlation is significant at the 0.01 level (2-tailed).

between the degree of bullying and self-esteem $\left(r=-0.364^{* *}\right)$ and positive correlation between the degree of bullying and stress $(r=0.406)$, anxiety and depression (DASS) $(r=0.389)$. As far as self-esteem is concerned, the meaning of this finding could be that the victims may become targets and may be unable to react due to low self-esteem. At the same time, there can be a reverse relation, i.e. the person gradually loses his/her self-esteem due to prolonged bullying. Similarly, as far as stress, anxiety and depression are concerned, there seems to be a linear regression, because when workplace bullying increases, so does stress, anxiety and depression.

In order to confirm the test's conceptual validity, we performed an exploratory factor analysis with orthogonal rotation. The results and the scree plot are presented in Figure 1 and Table 5.

According to the analysis results, there are 4 factors with eigenvalue $>1$, which account for $58.15 \%$ of the variance. However, the questions' variation per factor on the basis of their content and the scree plot revealed high probability of two principal factors' presence. The remaining two appear to be sub-factors of the two principal factors, and the questions' content is similar. Based on the above conclusion and the relation between the two principal factors, we performed a new factor analysis, in order to detect two factors within our sample's answers. Results are presented in Table 6.

The results seem to confirm the test's original factorial structure with two principal factors. Namely questions $1,3,4,11,12,13,14,16,18,19,21$ seem to pertain to the work-related bullying factor, while questions 2, 5, 6, $7,8,9,10,15,17,20,22$ to the person and personality-related factor. In other standardizations, a third factor about physical abuse is noted, which is explored by question 22. As stated before, this question bears some issues and it refers more to school bullying than adult bullying. In our analysis, its loading is on the general factor of person-related bullying. This behavior is avoided among adults due to legal and social reasons. Within validity analysis, we performed another analysis by associating the entire scale (the total score of bullying) with an additional question (23) included in the questionnaire for this purpose. Question 23 provides the definition of bullying and asks the participants at the end of the questionnaire, to self-report the frequency of the experienced bullying at work. This question is included for two reasons: 1) most employees are not aware of the concept of bullying and they often confuse it with bad behavior; and 2) they may have experienced most bullying symptoms, but when they are prompted to realize that they have actually been victims of bullying, they deny it or they admit to it to a trivial level, because their experience is socially unacceptable. The results of the correlation analysis between the entire questionnaire and the specific question was $r=0.65^{* *}$ (see Table 7).

The correlation results showed high positive statistically significant correlation between question 23 and the overall score of the scale. Although this result was unexpected-according to bibliography-it could be explained by the fact that originally there were very few participants within our sample with high bullying scores (intense and frequent experiences).

Finally, the results show that gender, age, years of professional experience, height, weight, and optimism do not affect the phenomenon. The only demographic variable that seems to have an impact on bullying levels is 


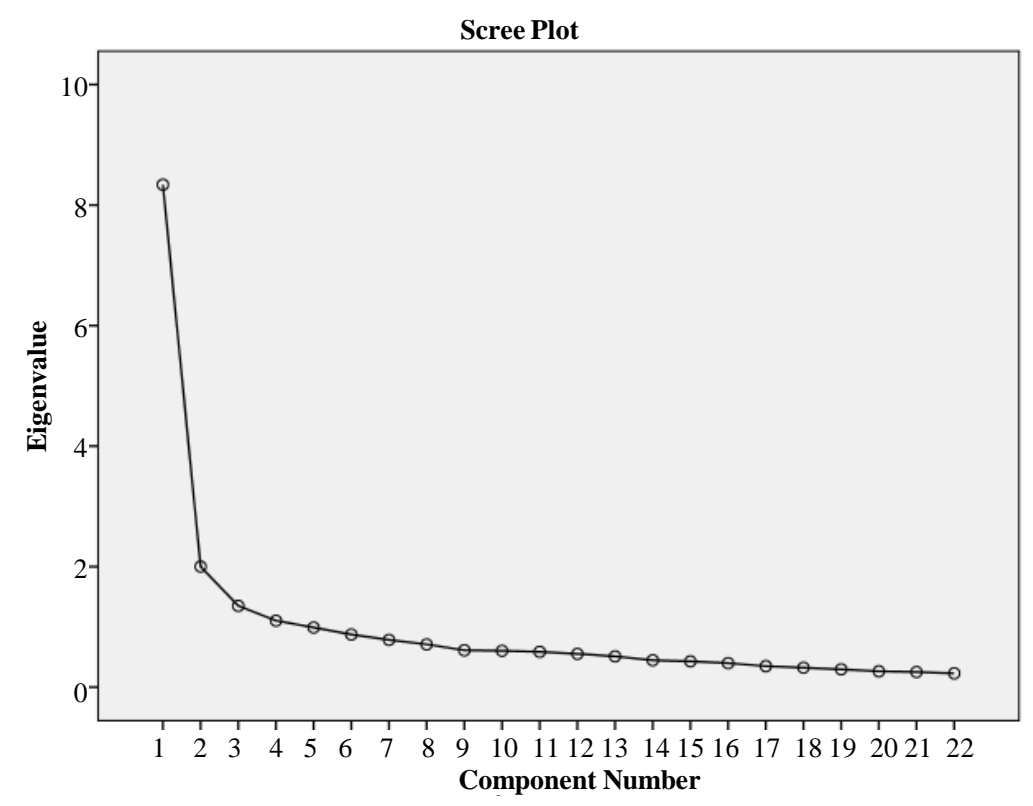

Figure 1. Scree plot of the factor analysis NAQ-22.

Table 5. Exploratory factor analysis of NAQ-22.

\begin{tabular}{|c|c|c|c|c|c|c|c|c|c|}
\hline \multirow{2}{*}{ Component } & \multicolumn{3}{|c|}{ Initial Eigenvalues } & \multicolumn{3}{|c|}{ Extraction Sums of Squared Loadings } & \multicolumn{3}{|c|}{ Rotation Sums of Squared Loadings } \\
\hline & Total & $\%$ of Variance & Cumulative \% & Total & $\%$ of Variance & Cumulative \% & Total & $\%$ of Variance & Cumulative \% \\
\hline 1 & 8.339 & 37.907 & 37.907 & 8.339 & 37.907 & 37.907 & 4.405 & 20.024 & 20.024 \\
\hline 2 & 2.000 & 9.092 & 46.999 & 2.000 & 9.092 & 46.999 & 3.748 & 17.037 & 37.062 \\
\hline 3 & 1.349 & 6.133 & 53.132 & 1.349 & 6.133 & 53.132 & 2.754 & 12.519 & 49.581 \\
\hline 4 & 1.103 & 5.015 & 58.147 & 1.103 & 5.015 & 58.147 & 1.885 & 8.566 & 58.147 \\
\hline 5 & 0.989 & 4.497 & 62.644 & & & & & & \\
\hline 6 & 0.873 & 3.966 & 66.610 & & & & & & \\
\hline 7 & 0.785 & 3.568 & 70.177 & & & & & & \\
\hline 8 & 0.710 & 3.228 & 73.406 & & & & & & \\
\hline 9 & 0.612 & 2.783 & 76.188 & & & & & & \\
\hline 10 & 0.603 & 2.742 & 78.931 & & & & & & \\
\hline 11 & 0.587 & 2.668 & 81.599 & & & & & & \\
\hline 12 & 0.553 & 2.513 & 84.112 & & & & & & \\
\hline 13 & 0.512 & 2.325 & 86.438 & & & & & & \\
\hline 14 & 0.447 & 2.031 & 88.469 & & & & & & \\
\hline 15 & 0.428 & 1.945 & 90.415 & & & & & & \\
\hline 16 & 0.398 & 1.809 & 92.223 & & & & & & \\
\hline 17 & 0.349 & 1.584 & 93.808 & & & & & & \\
\hline 18 & 0.323 & 1.469 & 95.276 & & & & & & \\
\hline 19 & 0.296 & 1.345 & 96.622 & & & & & & \\
\hline 20 & 0.263 & 1.197 & 97.819 & & & & & & \\
\hline 21 & 0.251 & 1.142 & 98.961 & & & & & & \\
\hline 22 & 0.229 & 1.039 & 100.000 & & & & & & \\
\hline
\end{tabular}

Extraction method: principal component analysis. 
Table 6. Loadings of the questions in the proposed factorial structure No 2 of NAQ-22.

\begin{tabular}{|c|c|c|}
\hline \multicolumn{3}{|c|}{ Structure Matrix } \\
\hline & \multicolumn{2}{|c|}{ Component } \\
\hline & 1 & 2 \\
\hline NA1 & 0.461 & \\
\hline NA2 & & 0.647 \\
\hline NA3 & 0.590 & \\
\hline NA4 & 0.687 & \\
\hline NA5 & & 0.672 \\
\hline NA6 & & 0.572 \\
\hline NA7 & & 0.817 \\
\hline NA8 & & 0.703 \\
\hline NA9 & & 0.683 \\
\hline NA10 & & 0.554 \\
\hline NA11 & 0.701 & \\
\hline NA12 & 0.664 & \\
\hline NA13 & 0.734 & \\
\hline NA14 & 0.725 & \\
\hline NA15 & & 0.644 \\
\hline NA16 & 0.748 & \\
\hline NA17 & & 0.607 \\
\hline NA18 & 0.794 & \\
\hline NA19 & 0.731 & \\
\hline NA20 & & 0.672 \\
\hline NA21 & 0.652 & \\
\hline NA22 & & 0.669 \\
\hline
\end{tabular}

Extraction method: principal component analysis. Rotation method: oblimin with kaiser normalization.

Table 7. Criterion validity analysis of NAQ-22 with the self-report 23rd question about bullying.

\begin{tabular}{cccc}
\hline \multicolumn{2}{c}{ Correlations } & & \\
\hline & & NATOTAL & NA23 \\
\hline NATOTAL & Pearson Correlation & 1 & $0.645^{* *}$ \\
& Sig. (2-Tailed) & & 0.000 \\
N & 229 & 229 \\
NA23 & Pearson Correlation & $0.645^{* *}$ & 1 \\
& Sig. (2-Tailed) & 0.000 & 258 \\
\hline
\end{tabular}

${ }^{* *}$ Correlation is significant at the 0.01 level (2-tailed).

the type of school. Specifically, teachers at private schools experience higher levels of bullying that their colleagues at other types of schools.

\section{Discussion}

The purpose of this study was to validate Negative Acts Questionnaire-Revised (NAQ-22) in a Greek Sample. 265 or $90 \%$ of the distributed questionnaires were returned. NAQ-22 combines the operational method (22 items) 
with the subjective or self-labelling method (23rd item). The rate of the participants who stated bullying behaviors according to the operational method was $14.4 \%$, while with the subjective or self-labelling method the same rate was $16.7 \%$.

In a similar research conducted in Greece with NAQ-32, on employees in the private sector, 13\% (operational method) or 7.3\% (self-reporting technique) of the respondents fall within the victims' category (Galanaki \& Papalexandris, 2011). In Germany, $17.4 \%$ of the study's teachers stated that they have been bullied and the students were not included in the perpetrators. In Turkey, the respective rate was $4.1 \%$ while other studies reveal high rates of workplace harassment in the teaching sector (Astrauskaite et al., 2010; Cemaloglu \& Necati, 2007).

In question 22, all participants stated that they had not been physically abused. This result was expected since adult bullying at workplace concerns psychological and not physical abuse (Keashl \& Harvey, 2005). Physical aggression only happens occasionally (Lim, 2011). On the contrary, physical abuse in school bullying is the most dominant negative act (Olweus, 1994).

Cronbach's internal consistency analysis confirmed the NAQ-22 scale's reliability. Specifically, Cronbach's alpha was 0.915. The standardization of NAQ-32 in Greece, showed Cronbach's alpha $=0.904$ (Galanaki \& Papalexandris, 2011). The criterion validity analysis of NAQ-22 with the criteria of stress, anxiety, depression and self-esteem confirmed that the scale is valid. When the degree of bullying increases, self-esteem levels of the victim drop whereas stress, anxiety and depression levels rise. Our finding are congruent with those of studies on other workplace sectors, according to which, workplace bullying is strongly correlated with stress symptoms (Di Martino et al., 2003) low self-esteem and depression (Hoel \& Cooper, 2000; Johnson, 2009; Matthiesen et al., 2003; Mikkelsen \& Einarsen, 2001).

The results show that gender, age, years of professional experience, height, weight, and optimism do not affect the phenomenon, even though other studies have come to opposite findings (Abbas Erturk, 2013; Di Martino et al., 2003). The only demographic variable that seems to have an impact on bullying levels is the type of school. Specifically, teachers at private schools experience higher levels of bullying than their colleagues at public schools. The above findings are not pursuant to previous studies, where younger teachers appear to be more exposed to harassment compared to their older colleagues (Russo et al., 2008), men experience harassing behaviors more often than women, (Abbas Erturk, 2013) and teachers working at public primary schools are more often bullied (Asiye Toker Gökçe, 2012). Furthermore, we should be cautious about high levels of bullying in private schools, since this type of schools is represented by a very low percentage $(1.90 \%$ private schools and $4.20 \%$ crammer schools) in our sample.

As far as limitations are concerned there are three basic limitations in our study which lead to future research directions: Firstly, the majority of the sample's individuals, $86.90 \%$, were secondary school teachers, while only $12.7 \%$ were primary school teachers. Secondly, the relatively small sample of 265 teachers was mainly from Athens (83.10\%) and only 16.90\% from the regional areas of Greece. Thirdly, teachers at private schools account for very low percentage (under-represented). Nevertheless we believe that these limitations do not decrease the importance of the findings. Thus, the research provides sufficient data for the reliability and validity of NAQ-22. It verifies the data of previous standardization studies and portrays a representative layout of the phenomenon in Greek Teachers.

\section{Conclusion and Future Studies}

Our study is useful for reference regarding the use of this tool in future studies for the examination of the work place bullying, especially for teachers. It represents data concerning the standardization of the test in the Greek Population with high internal consistency (Cronbach's a $=0.915$ ) and criterion validity. The present study could lead to future studies in relation to workplace bullying for different working groups such as nurses, caregivers, doctors and perhaps to a larger scale study for the phenomenon in the private and public sector.

\section{References}

Abbas, E. (2013). Mobbing Behayiour: Victims and the Affected. Educational Sciences: Theory \& Practice, 13. www.edam.com.tr/estp

Andreou E., Alexopoulos E., Lionis C., Varvogli L., Gnardellis C., Chrousos G. and Darviri C. (2011). Perceived Stress Scale: Reliability and Validity Study in Greece. International Journal of Environmental Research and Public Health, 8, 3287-3298. http://dx.doi.org/10.3390/ijerph8083287 
Apospori E., \& Papalexandris N. (2008). Workplace Bulling and Organizational Culture: A Multi-Level Approach. 6th International Conference on Workplace Bulling, 4-6 June 2008, Montreal, 63.

Asiye Toker Gökçe (2012). Mobbing at Elementary Schools in Turkey. Mediterranean Journal of Social Sciences, 3 ,

Astrauskaite, M., Perminas, A., \& Kern, R. M. (2010). Sickness, Colleagues’ Harassment in Teachers’ Work and Emotional Exhaustion. Medicina (Kaunas), 46, 628-34.

ATL Annual Conference (2011). A Quarter of Education Staff Have Been Bullied by Colleagues—ATL. http://www.atl.org.uk/

Beswick, J., Gore, J., \& Palferman, D. (2006). Bullying at Work: A Review of the Literature. Health and Safety Laboratory, WPS/06/04.

Blasé J., \& Blasé, J. (2006). Teachers’ Perspectives on Principal Mistreatment Teacher Education Quarterly.

Čech, T. (2010). Mobbing in Primary Schools: Effects on Interpersonal Relationships and School Climate, Options for Protection and Prevention. In E. Řehulka, (Ed.), School and Health 21 Papers on Health Education (pp. 347-356). Brno: Masarykova Univerzita.

Cemaloglu, \& Necati (2007). The Exposure of Primary School Teachers to Bulling: An Analysis of Various Variables. Social Behavior and Personality: An International Journal, 35, 789-802. http://dx.doi.org/10.2224/sbp.2007.35.6.789

Di Martino, V., Hoel, H., \& Cooper, C. L. (2003). Preventing Violence and Harassment in the Workplace (Report). European Foundation for the Improvement of Living and Working Conditions.

Djurkovic, N. (2004). Workplace Behavior and Staff Interactions: A Case Study of Teachers in Victorian Secondary Schools. 4th International Conference on Bullying and Harassment in the Workplace, Bergen, 28-29 June 2004.

Einarsen, S., Raknes, B. I., \& Matthiesen, S. B. (1994). Bullying and Harassment at Work and Their Relationships to Work Environment Quality: An Exploratory Study. European Work and Organizational Psychologist, 4, 381-401. http://dx.doi.org/10.1080/13594329408410497

Einarsen, S., \& Skogstad, A. (1996). Bullying at Work: Epidemiological Findings in Public and Private Organizations. European Journal of Work and Organizational Psychology, 5, 185-201. http://dx.doi.org/10.1080/13594329608414854

Einarsen, S., \& Hoel, H. (2001). The Negative Acts Questionnaire: Development, Validation and Revision of a Measure of Bullying at Work. 10th European Congress on Work and Organizational Psychology, Prague, 16-19 May 2001.

Einarsen, S., Hoel, H., \& Notelaers, G. (2009). Measuring Exposure to Bullying and Harassment at Work: Validity, Factor Structure and Psychometric Properties of the Negative Acts Questionnaire-Revised. Work \& Stress, 23, 24-44. http://dx.doi.org/10.1080/02678370902815673

Einarsen, S., Hoel, H., Zapf, D., \& Cooper, C. L. (2011). The Concept of Bullying and Harassment at Work. The European Tradition. In S. Einarsen, H. Hoel, D. Zapf, \& C. L. Cooper (Eds.), Bulling and Harassment in the Workplace (p. 4). Boca Raton, FL: CRC Press.

Ferrari, E. (2004). Raising Awareness on Women Victims of Mobbing: The Italian Contribution. DAPHNE Programme: Preventive Measures to Fight Violence against Children, Young People and Women, European Commission. http://ec.europa.eu/daphnetoolkit/mobbing

Galanaki, E., \& Papalexandris, N. (2011). Exploring Workplace Bullying in Greece: Frequency of Occurrence and Handling of Measurement Issues, under the Light of Previous Research Findings at the International Level. 11 April 2011, European Academy of Management Conference: Management Culture in the 21st Century. http://ssrn.com/abstract=1831425

Hoel, H., \& Cooper, C. L. (2000). Destructive Conflict \& Bullying at Work. Manchester: Manchester School of Management, University of Manchester, Institute of Science and Technology.

Hoel, H., Cooper, C. L., \& Faragher, B. (2001). The Experience of Bullying in Great Britain: The Impact of Organizational Status. European Journal of Work and Organizational Psychology, 10, 443-465. http://dx.doi.org/10.1080/13594320143000780

Hoel, H., Zapf, D., \& Cooper, G. L. (2002). Workplace Bulling and Stress. In P. Perrewe, \& D. Ganster (Eds.), Historical and Current Perspectives on Stress and Health (pp. 293-326). Bingley, West Yorkshire: Emerald Group Publishing Limited. http://dx.doi.org/10.1016/S1479-3555(02)02008-5

Johnson, S. L. (2009). International Perspectives on Workplace Bullying among Nurses: A Review. International Nursing Review, 56, 34-40. http://dx.doi.org/10.1111/j.1466-7657.2008.00679.x

Keashly, L. (2001). Interpersonal and Systemic Aspects of Emotional abuse at Work: The Target's Perspective. Violence and Victims, 16, 233-268.

Keashly, L., \& Harvey, S. (2005). Emotional Abuse in the Workplace. In S. Fox, \& P. E. Spector (Eds.), Counterproductive Workplace Behavior: Investigations of Actors and Targets (pp. 201-235). Washington DC: American Psychological Association. http://dx.doi.org/10.1037/10893-009

Kivimaki, M., Virtanen, M., Vartia, M., Elovainio, M., Vahtera, J., \& Keltikangas-Jarvinen, L. (2003). Workplace Bullying 
and the Risk of Cardiovascular Disease and Depression. Occupational and Environmental Medicine, 60, 779-783. http://dx.doi.org/10.1136/oem.60.10.779

Leymann, H. (1990). Mobbing and Psychological Terror at Workplaces. Violence and Victims, 5, 119-126.

Lim, J. J. C. (2011). A Cross-Cultural Comparison and Examination of Workplace Bullying in Singapore and the United States (p. 13). Houston, TX: University of Houston.

Lutgen-Sandvik, P., Tracy, S. J., \& Alberts, J. K. (2007). Burned by Bullying in the American Workplace: Prevalence, Perception, Degree and Impact. Journal of Management Studies, 44, 837-862. http://dx.doi.org/10.1111/j.1467-6486.2007.00715.x

Lutgen-Sandvik, P., \& Tracy, S. J. (2011). Answering Five Key Questions about Workplace Bullying. How Communication Scholarship Provides Thought Leadership for Transforming Abuse at Work. Management Communication Quarterly, 26, 3-47. http://mcq.sagepub.com/content/26/1/3 http://dx.doi.org/10.1177/0893318911414400

Lyrakos, G. N., Arvaniti, C., Smyrnioti, M., \& Kostopanagiotou, G. (2011). Translation and Validation Study of the Depression Anxiety Stress Scale in the Greek General Population and in a Psychiatric Patient's Sample. European Psychiatry, 26, 1731. http://dx.doi.org/10.1016/S0924-9338(11)73435-6

Matthiesen, S. B., Aasen, E., Holst, G., Wie, K., \& Einarsen, S. (2003). The Escalation of Conflict: A Case Study of Bullying at Work. International Journal of Management and Decision Making, 4, 96-112.

Matthiesen, S. B., \& Einarsen, S. (2004). Psychiatric Distress and Symptoms of PTSD among Victims of Bullying at Work. British Journal of Guidance \& Counselling, 32, 335-356. http://dx.doi.org/10.1080/03069880410001723558

Matthiesen, S. B., \& Einarsen, S. (2007). Perpetrators and Targets of Bullying at Work: Role Stress and Individual Differences. Violence and Victims, 22, 735-753. http://dx.doi.org/10.1891/088667007782793174

Mikkelsen, E. G., \& Einarsen, S. (2001). Bullying in Danish Work-Life: Prevalence and Health Correlates. European Journal of Work and Organizational Psychology, 10, 393-413. http://dx.doi.org/10.1080/13594320143000816

Moayed, F. A., Daraiseh, N., Shell, R., \& Salem, S. (2006). Workplace Bullying: A Systematic Review of Risk Factors and Outcomes. Theoretical Issues in Ergonomics Science, 7, 311-327. http://dx.doi.org/10.1080/14639220500090604

Nielsen, M. B., Notelaers, G., \& Einarsen, S. (2011). Measuring Exposure to Workplace Bullying. In S. Einarsen, H. Hoel, D. Zapf, \& C. L. Cooper (Eds.), Bulling and Harassment in the Workplace (2nd ed.). Boca Raton, FL: CRC Press.

Nolfe, G., Triassi, M., Cappuccio, A., Carbone, U., \& Nolfe, G. (2012). The Naples-Questionnaire of Work Distress (nQWD): Bullying at Workplace, Organizational Dysfunctions and Bio-Psychosocial Effects. Open Journal of Psychiatry, 2, 77-81.

Olweus, D. (1994). Bullying at School: Basic Facts and an Effective Intervention Programme. Global Health Promotion, 1 , 27-31. http://ped.sagepub.com/content/1/4/27.extract?patientinformlinks=yes\&legid=spped;1/4/27

Russo, A., Milić, R., Knežević, B., Mulić, R., \& Mustajbegović, J. (2008). Harassment in Workplace among School Teachers: Development of a Survey. Croatian Medical Journal, 49, 545-552. http://dx.doi.org/10.3325/cmj.2008.4.545

Salin, D. (2003). Ways of Explaining Workplace Bullying: A Review of Enabling, Motivating, and Precipitating Structures and Processes in the Work Environment. Human Relations, 56, 1213-1232. https://helda.helsinki.fi/bitstream/handle/10227/283/salin_HR_2003.pdf

Sharon, L. E., \& O’Connell, C. F. (2007). Exploring Bullying: Implications for Nurse Educators. Nurse Education in Practice, 7, 26-35. http://dx.doi.org/10.1016/j.nepr.2006.03.004

Vartia, M. A. L. (2001). Consequences of Workplace Bullying with Respect to the Well-Being of Its Targets and the Observers of Bullying. Scandinavian Journal of Work, Environment \& Health, 27, 63-69.

Zapf, D., Escartin, J., Einarsen, S., Hoel, H., \& Vartia, M. (2011). Empirical Findings on Prevalence and Risk Groups of Bullying in the Workplace. In S. Einarsen, H. Hoel, D. Zapf, \& C. L. Cooper (Eds.), Bulling and Harassment in the Workplace (2nd ed., pp. 75-105). Boca Raton, FL: CRC Press. 
Scientific Research Publishing (SCIRP) is one of the largest Open Access journal publishers. It is currently publishing more than 200 open access, online, peer-reviewed journals covering a wide range of academic disciplines. SCIRP serves the worldwide academic communities and contributes to the progress and application of science with its publication.

Other selected journals from SCIRP are listed as below. Submit your manuscript to us via either submit@scirp.org or Online Submission Portal.
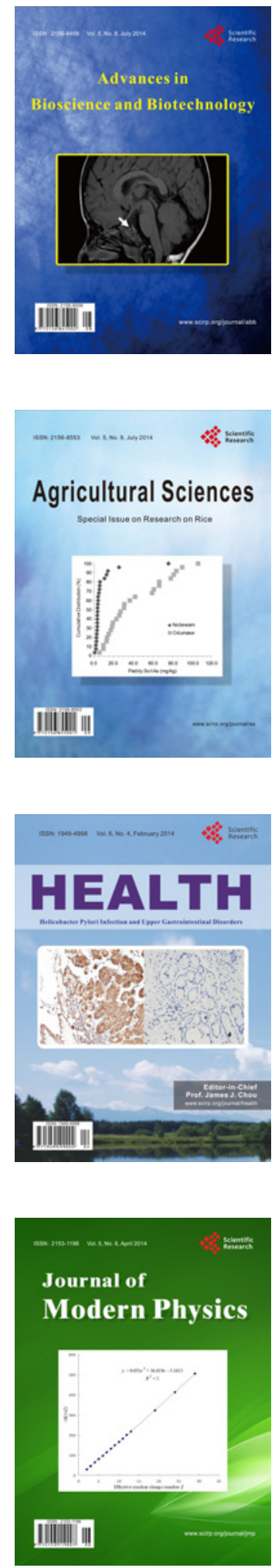
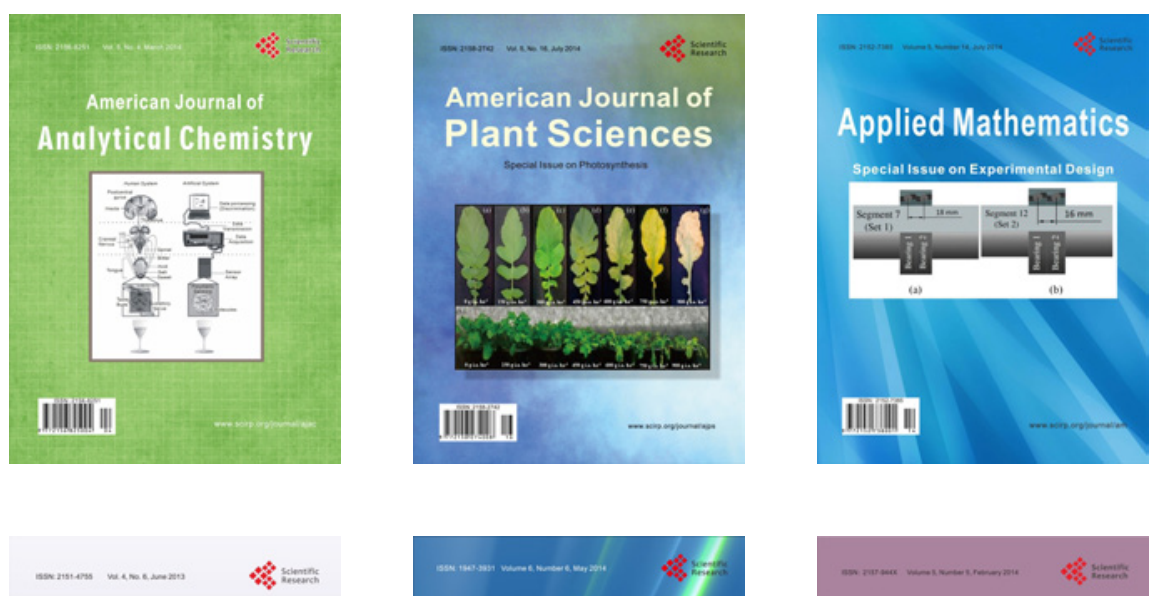

Creative Education
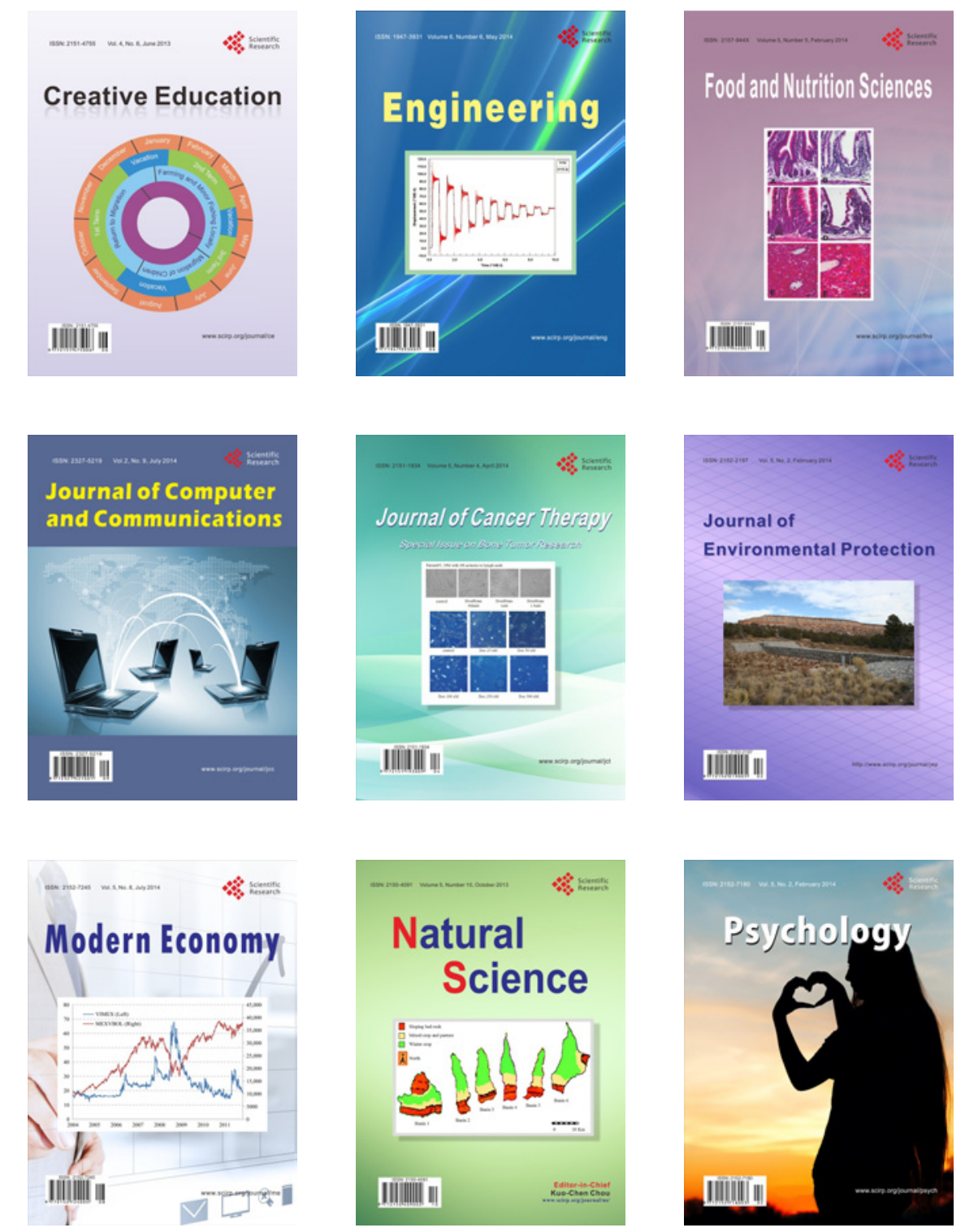